\title{
Calcitonin Gene-related Peptide Inhibits Tumor Cell Proliferation of Hepatocellular Carcinoma Cells Through the Ras/MEK/ERK Pathway
}

\author{
Masaki Hara ${ }^{1}$, Yuko Takeba ${ }^{2}$, Minoru Watanabe ${ }^{3}$, Yuki Ohta ${ }^{2}$, \\ Takehito Ohtsubo ${ }^{4}$, Toshio Kumai ${ }^{1}$, and Naoki Matsumoto ${ }^{2}$
}

(Received for Publication: September 17, 2015)

\begin{abstract}
Calcitonin gene-related peptide (CGRP) is widely distributed in the central and peripheral nervous systems and regulates physiological functions. Several neuropeptides are involved in the development and progression of hepatocellular carcinoma (HCC), although the role of CGRP in HCC pathogenesis is unclear. This study attempted to clarify the effects of CGRP on tumor progression in HCC cells. CGRP and its receptors, calcitonin receptor-like receptor and receptor activity-modifying protein-1, were expressed in HCC tissues and HCC cell lines. When Huh7 cells were cultured with CGRP $10^{-10}$ and $10^{-9} \mathrm{M}$ for $24 \mathrm{~h}$, cell proliferation was significantly inhibited. In addition, the total and phosphorylated protein levels of Ras and mitogen-activated protein kinase (MAPK) family proteins, MAP kinase (MEK) $1 / 2$ and extracellular signal-regulated kinase (ERK) 1/2, were also inhibited by CGRP $10^{-10} \mathrm{M}$ incubation. CGRP significantly increased the protein levels of cAMP response element binding protein (CREB) and its phosphorylated form in the nuclei of Huh 7 cells. Furthermore, pretreatment of CGRP receptor antagonist $\mathrm{CGRP}_{8-37}$ abolished the increases in CREB and pCREB protein levels in the nuclei of Huh7 cells. In addition, pretreatment of CGRP $_{8-37}$ and cAMP inhibitor Rp-cAMP tended to reverse the ERK inhibition in Huh 7 cells cultured with CGRP. These results suggest that CGRP inhibits HCC cell proliferation via CREB activation and Ras/MEK/ERK pathway. CGRP may play an important role in the amelioration of cancer progression.
\end{abstract}

Key words

calcitonin-gene related peptide, hepatocellular carcinoma, Huh7, ERK, CREB

\section{Introduction}

The release of biochemical mediators such as cortisol, catecholamines, and neuropeptides is induced by a variety of physiological changes and enhances the immune response ${ }^{1,2)}$. Although such mediators generally exert beneficial effects, they often trigger pathological processes and contribute to the development and progression of various diseases, including cancer $^{3)}$. Several neuropeptides show antipro- liferative activity in tumor models and cell lines ${ }^{3)}$. In addition, direct antitumor effects are mediated through their receptors ${ }^{4}$. Thus, some mediators and receptors can become novel targets for antitumor therapy.

Hepatocellular carcinoma (HCC) is the most common cause of cancer-related death, and its incidence is increasing worldwide. Due to the known risk factors, mainly hepatitis $\mathrm{B}$ and $\mathrm{C}$ viruses (HBV and $\mathrm{HCV}$ ), there is a rationale for a chemopreventive ap-

\footnotetext{
1 Department of Genomics, St Marianna University Graduate School of Medicine

2 Department of Pharmacology, St Marianna University School of Medicine

3 Institute for Animal Experimentation, St Marianna University Graduate School of Medicine

4 Division of Gastroenterological Surgery, St Marianna University Graduate School of Medicine
} 
proach to treat $\mathrm{HCC}^{5)}$. Chemotherapeutic agents currently used to treat advanced solid tumors are associated with significant toxicity. If neuropeptides secreted in vivo could be used as antitumor agents, those adverse effects might be reduced.

Therefore, the relationship between neuropeptide activity and HCC development must be clarified. To elucidate the roles of neuropeptides in the pathogenesis of HCC, we focused on the activity of calcitonin gene-related peptide (CGRP) as a novel target for antitumor therapy. The 37-amino acid neuropeptide CGRP is a potent vasodilator and mitogen involved in cardiovascular and neuronal physiology and neurogenic inflammation ${ }^{6}$.

The rat hepatobiliary tract is innervated by CGRP- and CGRP/SP/TK-immunoreactive fibers ${ }^{7)}$. However, the expression and roles of CGRP have not yet been studied in patients with HCC. Receptors for neuropeptides are overexpressed in several human tumors ${ }^{8)}$. Somatostatin analogues are used in the treatment of HCC due to the presence of somatostatin receptors in $\mathrm{HCC}$ cells ${ }^{8), 9}$. The calcitonin peptide family, including CGRP and adrenomedullin, are calcitonin receptor-like receptor (CLR) and receptor activity-modifying proteins (RAMPs) ${ }^{10)}$. The cellular distribution of CGRP receptors in hepatocytes and HCC cells is still unknown.

In this study, we characterized the expression of CGRP and its receptor in HCC. In addition, we explored the effects of CGRP in HCC development or progression.

\section{Materials and Methods}

\section{Materials}

CGRP and the CGRP receptor antagonist CGRP $_{8-37}$ were purchased from Sigma (St. Louis, MO, USA) and the cAMP antagonist Rp-cAMPS was obtained from the Biology Life Science Institute (Bremen, Germany). Antibodies (Abs) used in this study were: rabbit anti-extracellular signal-regulated kinase (ERK) polyclonal Ab, mouse anti-phosphorylated (p)ERK monoclonal Ab, rabbit anti-mitogen-activated protein kinase (MEK)-1 polyclonal $\mathrm{Ab}$, goat anti-pMEK polyclonal Ab (Santa Cruz Biotechnology, Santa Cruz, CA, USA), rabbit anti-Ras monoclonal $\mathrm{Ab}$, rabbit anti-cAMP responsive element binding protein (CREB) monoclonal Ab, rabbit antipCREB polyclonal Ab (Abcam, Tokyo, Japan), and mouse anti- $\alpha$-tubulin monoclonal Ab (Wako, Tokyo, Japan).

\section{Human liver tissues}

Human HCC tissues were obtained from patients undergoing partial hepatectomy in St. Marianna University School of Medicine Hospital after written informed consent was obtained from each patient prior to surgery. The tissues were immediately frozen in liquid nitrogen after resection. Normal hepatic tissues were obtained from the organs of Caucasian and Hispanic transplantation donors and supplied by the National Disease Research Interchange (Philadelphia, PA, USA) through the Biomedical Research Institute, Human and Animal Bridging Research Organization (Chiba, Japan). This study protocol was approved by the St. Marianna University School of Medicine Ethics Committee (approval number 1207).

\section{Immunohistochemistry}

Normal liver tissues and HCC tissues fixed in $10 \%$ formalin were embedded in paraffin and then sliced $3 \mu \mathrm{m}$ thick. Paraffin-embedded samples were deparaffinized in xylene and rehydrated in graded ethanol. Immunoreactivity in sections was demonstrated using a Dako Envision system (Carpinteria, CA, USA) according to the manufacturer's instructions.

\section{RNA extraction and reverse-transcription poly- merase chain reaction}

Total RNA was extracted using a commercial kit (RNeasy Mini, Qiagen, Germantown, MD, USA). The cDNA was synthesized from $1 \mu \mathrm{g}$ of total RNA using a RETROscript kit (Ambion Inc., Austin, TX, USA). cDNA was amplified in the polymerase chain reaction (PCR) on a thermal cycler (Life Tech, Foster City, CA, USA) The PCR reactions were performed in a Bio-Rad PCR System PTC-1152 thermal cycler (Tokyo, Japan) under the following conditions: $95^{\circ} \mathrm{C}$ for $30 \mathrm{~s}$, followed by 35 cycles of denaturation at $95^{\circ} \mathrm{C}$ for $30 \mathrm{~s}$; annealing at $55^{\circ} \mathrm{C}$ for $60 \mathrm{~s}$; extension at $72^{\circ} \mathrm{C}$ for $60 \mathrm{~s}$; and inactivation at $72^{\circ} \mathrm{C}$ for $10 \mathrm{~min}$. The amplified products were resolved in a $2 \%$ agarose gel and visualized by Ultra Power DNA staining (Gellex International Ltd., Tokyo, Japan).

The primers for CGRP type-1 receptor were 5'GACATCCAGCAAGCAACAGA-3' (sense) and 5'CATGCCAAGCAATGGCACC-3' (antisense) and the primers for RAMP-1 were 5'-CTGCCAGGAGGCTAACTACG-3' (sense) and 5'CCTCAGTGCGCTTGCTCT-3' (antisense). GAPDH was used as a housekeeping gene. The primers for 
GAPDH were 5'-GACAACTTTGGTATCGTGGA-3' (sense) and 5'-TACCAGGAAATGAGCTTGAC-3' (antisense).

\section{Cell lines and cell culture}

The HCC Huh7 and hepatoblastoma $\mathrm{HepG}_{2}$ cell lines were obtained from the Riken Gene Bank (Tsukuba, Japan). The Huh7 and $\mathrm{HepG}_{2}$ cells were cultured with RPM1-1640 medium (Sigma, Osaka, Japan) containing $10 \%$ fetal calf serum (Invitrogen, Grand Island, NY, USA), with streptomycin 100 $\mu \mathrm{g} / \mathrm{ml}$ and penicillin 100 units $/ \mathrm{ml}$ at $37^{\circ} \mathrm{C}$ under a humidified atmosphere of $5 \% \mathrm{CO}_{2}$ and $95 \% \mathrm{O}_{2}$. After seeding, the cells were incubated for $24 \mathrm{~h}$. Then, the cells were cultured with CGRP $\left(10^{-12}-10^{-8} \mathrm{M}\right)$.

\section{Cell proliferation assay}

Huh7 cells $\left(4 \times 10^{4}\right)$ were cultured with CGRP for 4, 16, and $24 \mathrm{~h}$ in 96-well flat Costar plates. (Corning International, Tokyo, Japan) in $200 \mu \mathrm{l}$ of RPM1-1640 medium. After incubation, $20 \mu \mathrm{l}$ of [3(4, 5-dimethylthiazol-2-yl)-5-(3-carboxymethoxyphenyl)-2-(4-sulfophenyl)-2H-tetrazolium inner salt (MTS)] substrate was added to each well. Cell proliferation was evaluated using the CellTiter 96 AQueous One Solution Cell Proliferation Assay (Promega, Madison, WI, USA) following the manufacturer's instructions. Absorbance was measured at $490 \mathrm{~nm}$ with a microplate reader (Multiscan, Thermo Labsystems, Ventaa, Finland). The proliferation rate was expressed as the ratio of optical density of the treated to the control cells.

\section{Western blot analysis}

Whole proteins of Huh7 cells were extracted with cell lysing buffer (Tris- $\mathrm{HCl} 50 \mathrm{mM}, \mathrm{pH} 7.4$, EGTA $1 \mathrm{mM}, 0.001 \%$ leupeptin), and the nuclear proteins in the cells were separated using a commercial kit (NE-PER nuclear and cytoplasmic extraction kit, Pierce Biotechnology, Rockford, IL, USA). The protein concentration was measured using a Bio-Rad protein assay kit (Bio-Rad, Hercules, CA, USA). The samples $(25 \mu \mathrm{g})$ were resolved on $10 \%$ sodium dodecyl sulfate-polyacrylamide gel electrophoresis. Thereafter, the membrane was blocked with 5\% skim milk in Tris-buffered saline containing Tween 20 ( $\mathrm{NaCl} 150 \mathrm{mM}$, Tris-HCl $100 \mathrm{mM}, \mathrm{pH}$ 7.5, Tween $0.5 \%$ ) overnight at $4{ }^{\circ} \mathrm{C}$. The blots were allowed to stand with the first $\mathrm{Ab}$ for $2 \mathrm{~h}$ at room temperature. Anti- $\alpha$-tubulin polyclonal Ab (Wako, Osaka, Japan) was used as the loading control. Reactive proteins were viewed under enhanced chemiluminescence (ImmunoStar, Wako). The intensity of the detected bands was analyzed using the C-DiGit Chemiluminescent Western Blot Scanner (LI-COR, Lincoln, NE, USA). Quantitative results of proteins detected were determined by densitometric analysis. Protein levels are expressed as the percentage of the values in untreated cells (controls).

\section{Statistical analysis}

All results are expressed as mean \pm SEM. Statistical analysis was performed using Kyplot software (version 5.0, Kyeus Lab, Tokyo, Japan). Statistical differences were determined using the Dwass-type Steel multiple-comparison method. A $p$ value of less than 0.05 was assumed to represent a statistically significant difference.

\section{Results}

\section{Immunohistochemistry of CGRP in HCC tissues}

We first studied the localization of CGRP protein in the hepatic tissues from patients with HCC. Etiological factors of HCC include HBV or HCV infection, and HCC is negative for both hepatitis B surface antigen and $\mathrm{HCV}$ antibody (non-B, non-C). We also examined liver tissues from patients with metastatic colorectal cancer and normal liver for comparison with HCC tissue.

Although marked localization of CGRP in normal liver tissue and that from patients with metastatic colorectal cancer was not observed, CGRP immunoreactivity was abundant in HCC tissue (Fig. 1A). Notable CGRP immunoreactivity was seen in both tumorous and nontumorous regions and was particularly high on the periphery of intrahepatic blood vessels in HCC tissues. In addition, these results indicate that CGRP is produced by HCC cells (Fig. 1B).

mRNA expression of CGRP receptors, CLR, and RAMP-1 in HCC tissue and cells

CGRP exerts its effects through a heterodimeric receptor comprised CLR and RAMP-1 ${ }^{11}$. CLR mRNA expression was seen in normal liver, the nontumorous region of $\mathrm{HCC}$ tissue, and $\mathrm{Huh} 7$ and HepG2 cells. However, CLR mRNA expression in the tumorous region of $\mathrm{HCC}$ tissue was relatively weak. Similar results on RAMP-1 mRNA expression were obtained (Fig. 2) 
$\mathbf{A}$
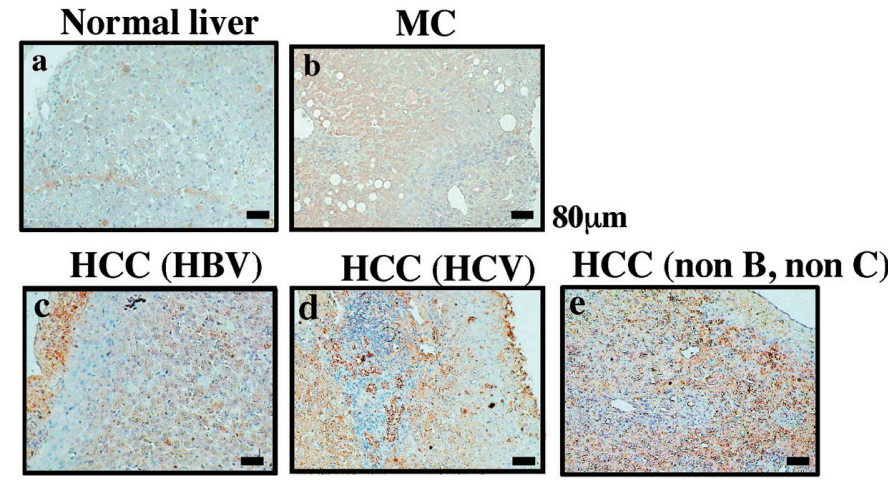

HCC (non B, non C)

B

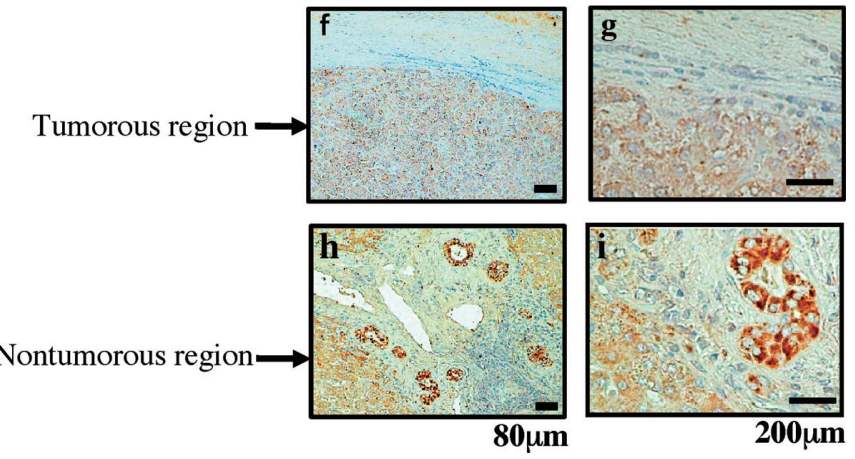

Figure 1. Immunohistochemical staining of calcitonin gene-related peptide (CGRP) in hepatocellular carcinoma (HCC) tissues with various etiologic factors. (A) CGRP expression in normal liver (a), colorectal cancer liver metastasis (b), hepatitis B virus-positive $\mathrm{HCC}$ (c), hepatitis $\mathrm{C}$ virus-positive $\mathrm{HCC}$ (d) and non-B, non-C HCC (e). Original magnification $\times 200$. The brown staining in the tissues indicates CGRP positivity. HCC tissues were obtained adjacent to the tumorous tissue. MC, metastatic carcinoma. (B) Immunohistochemical staining for CGRP in the tumorous and nontumorous regions of non-B, non-C HCC tissues. Original magnification $\times 200$ ( $\mathrm{f}$ and $\mathrm{h}$ ) and $\times 400$ (g and i). The nontumorous samples were taken at least $10 \mathrm{~cm}$ from the tumorous part of the liver and demonstrated pathologically to be free of tumor cells. All data are representative of tissues from 5 individual patients.

Cell proliferation in Huh7 and HepG2 cells cultured with CGRP

The MTS assay was used to examine the proliferation of Huh7 and HepG2 cells after culture with CGRP at concentrations ranging from $10^{-12} \mathrm{M}$ to $10^{-8}$ $\mathrm{M}$ for $24 \mathrm{~h}$. CGRP $10^{-10} \mathrm{M}(77.2 \pm 3.9 \%)$ and $10^{-9} \mathrm{M}$ $(80.8 \pm 4.5 \%)$ inhibited the proliferation of Huh7 cells compared with controls $(100.0 \pm 1.0 \%)$. There was a significant difference in the proliferation of Huh7 cells cultured with CGRP $10^{-12}$ M (95.2 $\pm 1.9 \%$ ) and $10^{-10} \mathrm{M}$. However, significant inhibition of HepG2 cell proliferation $(92.2 \pm 3.7 \%)$ compared with controls $(100.0 \pm 1.6 \%)$ was only seen when CGRP $10^{-10} \mathrm{M}$ was added to the culture medium (Fig. 3).

\section{Protein levels of CREB and ser-133 pCREB in Huh7 cells cultured with CGRP}

The action of neuropeptides is mediated by the binding to specific membrane-associated neuropeptide receptors. Most of these receptors belong to the G-protein-coupled receptor family ${ }^{12)}$. cAMP/CREB 

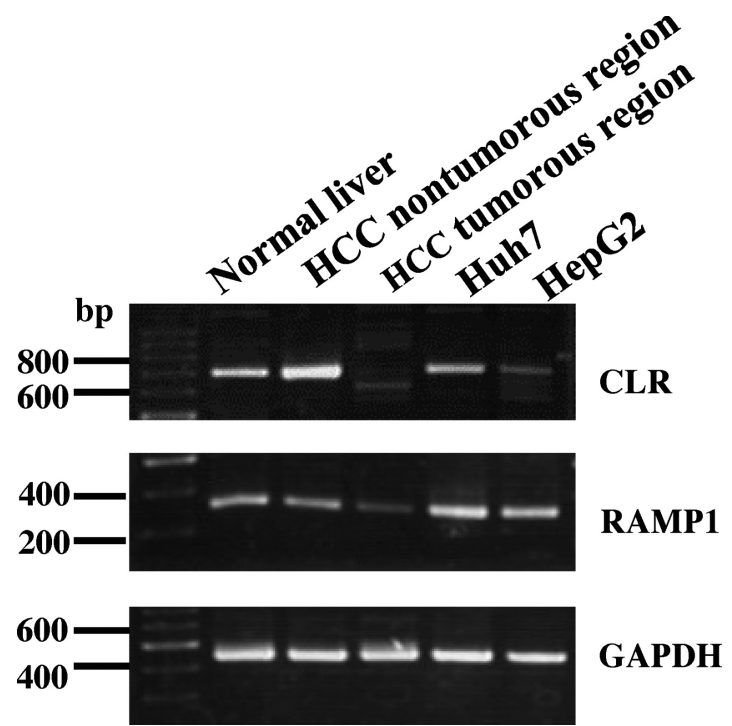

Figure 2. mRNA expression of CGRP receptors, CGRP type 1 receptor (CLR), and receptor activitymodifying protein (RAMP)-1 in HCC tissue and HCC cell lines. RNA extraction and RTPCR were performed in normal liver and HCC tissues and in Huh7 and HepG2 cells. Details are described in Materials and Methods. All data are representative of tissues from 5 individual patients. activation requires the phosphorylation of CREB on ser-133, and CREB is essential for the response of the CGRP gene ${ }^{13)}$. After Huh7 cells were cultured with CGRP for $15 \mathrm{~min}$, we examined the protein levels of total CREB and pCREB in the nuclei using Western blotting. As shown in Fig. 4, CREB protein levels in cells cultured with CGRP $10^{-10}$ M (270.9 $\pm 55.0 \%)$ were significantly higher than those in control cells $(100.0 \pm 33.6 \%)$. The protein levels of pCREB also significantly increased in cells cultured with CGRP $10^{-10} \mathrm{M}(352.9 \pm 67.1 \%)$ compared with those of the controls $(100.0 \pm 38.8 \%)$.

\section{Effects of the CGRP receptor antagonist CGRP $_{8-37}$ on CREB activation in Huh7 cells cultured with CGRP}

To examine whether CREB activation in CGRPtreated cells mediates the CGRP receptor, Huh7 cells were precultured with the CGRP receptor antagonist CGRP $_{8-37}$ for $1 \mathrm{~h}$, followed by incubation with CGRP $10^{-10} \mathrm{M}$ for $15 \mathrm{~min} . \mathrm{CGRP}_{8-37} 10^{-11} \mathrm{M}(91.7 \pm 17.7 \%)$ and $10^{-10} \mathrm{M}(85.0 \pm 18.2 \%)$ significantly inhibited the increases in CREB protein levels in Huh7 cells incubated with CGRP $10^{-10} \mathrm{M}(161.1 \pm 11.8 \%)$ CGRP $_{8-37}$ $10^{-11} \mathrm{M}(107.4 \pm 22.3 \%)$ also significantly inhibited the increases in pCREB protein levels in cells incubated with CGRP $(257.3 \pm 55.7 \%)$. The results seen in pCREB protein levels were similar to those of CREB protein levels. $\mathrm{CGRP}_{8-37}$ alone was confirmed to have no effect on CREB activation (Fig. 5). These results
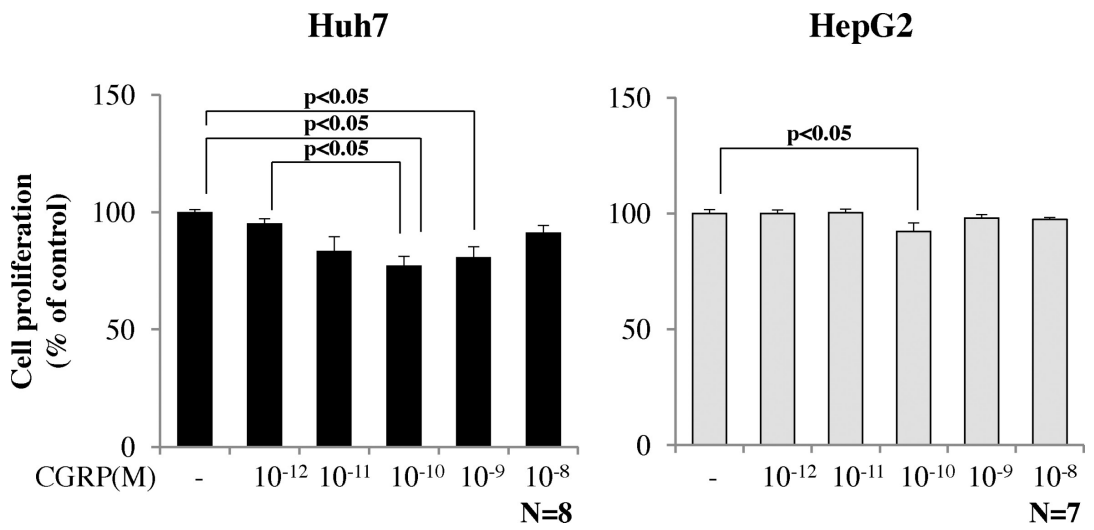

Figure 3. Cell proliferation in HCC cells cultured with CGRP. The cells $\left(4 \times 10^{4}\right)$ were cultured with CGRP in a 96-well plate for $24 \mathrm{~h}$. Cell proliferation was evaluated in the MTS assay. MTS was added to the medium after $2 \mathrm{~h}$ incubation with CGRP. Cell survival was detected by measuring absorbance at $490 \mathrm{~nm}$. Cell proliferation was expressed as the ratio of the optical density of CGRPcultured cells to that of controls. Data are expressed as mean \pm SEM. $p<0.05$ versus controls. 


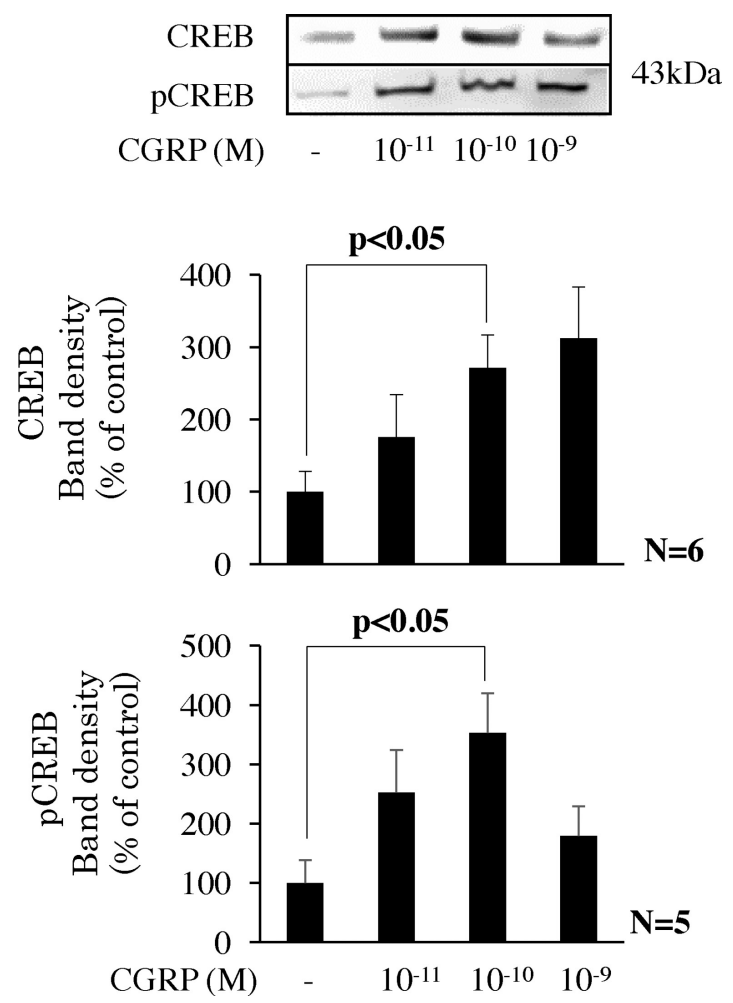

Figure 4. Protein levels of cAMP response element binding protein (CREB) and phosphorylated CREB (pCREB) in Huh7 cells cultured with CGRP. Huh7 cells were $80 \%$ confluent at the time of culture with CGRP $\left(10^{-11} \mathrm{M}, 10^{-10} \mathrm{M}\right.$, and $10^{-9}$ $\mathrm{M})$ for $15 \mathrm{~min}$, and then their nuclei were analyzed using Western blotting. Details are described in Materials and Methods. Data are expressed as mean \pm SEM. CGRP $10^{-10} \mathrm{M}$ significantly increased CREB and pCREB protein levels in the nuclei of Huh7 cells. $p<0.05$ versus controls.

indicate that CGRP stimulates CREB activation through its receptor.

Total and phosphorylated protein levels of Ras, MEK-1, and ERK in Huh7 cells cultured with CGRP

CGRP is known to regulate mitogen-activated protein kinase (MAPK) signaling ${ }^{13)}$. To clarify the mechanisms of the inhibition of HCC cell proliferation, protein levels of Ras, MEK-1, and ERK1/2 in Huh7 cells cultured with CGRP for $24 \mathrm{~h}$ were analyzed using Western blotting. CGRP $10^{-10} \mathrm{M}$ significantly inhibited the protein levels of Ras (38.6 $\pm 11.6 \%)$, MEK-1 (66.4 $\pm 11.2 \%)$, and ERK1/2 (60.8

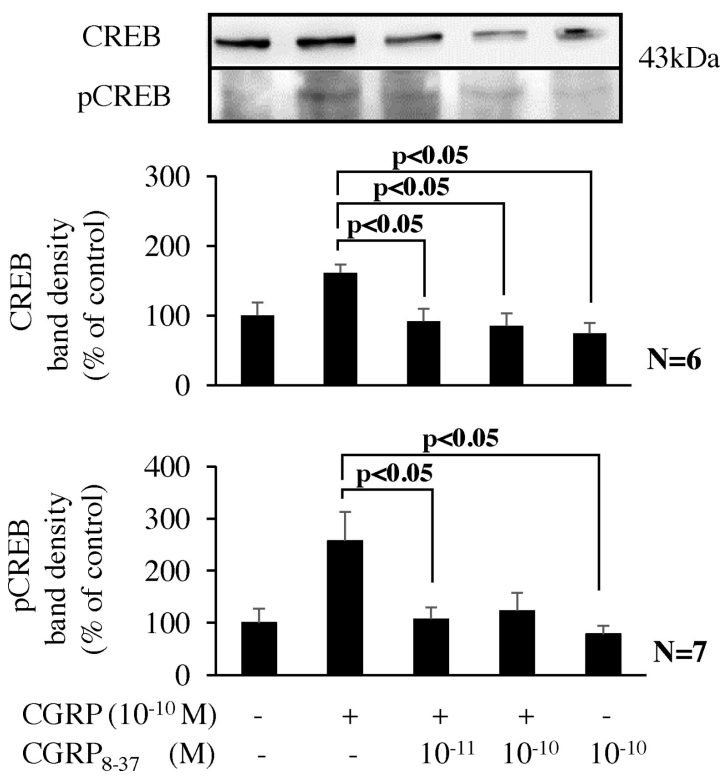

Figure 5. Effects of the CGRP receptor antagonist $\mathrm{CGRP}_{8-37}$ on protein levels of CREP and pCREB in Huh7 cells cultured with CGRP. Huh7 cells were precultured with $\mathrm{CGRP}_{8-37}$ $\left(10^{-11} \mathrm{M}\right.$ and $\left.10^{-10} \mathrm{M}\right)$ for $1 \mathrm{~h}$, followed by the addition of CGRP $\left(10^{-10} \mathrm{M}\right)$ for $15 \mathrm{~min}$, and the nuclei of cells were analyzed using Western blotting. Data are expressed as mean \pm SEM. $p$ $<0.05$ versus CGRP $10^{-10} \mathrm{M}$-cultured cells.

$\pm 7.7 \%$ ) compared with those of the respective controls (Ras, $100.0 \pm 3.1 \%$; MEK-1, $100.0 \pm 7.1 \%$; ERK, $100.0 \pm 9.8 \%$ ). The phosphorylation of MEK-1 $(56.7 \pm 11.0 \%)$ and ERK1/2 $(58.6 \pm 10.5 \%)$ was inhibited in Huh7 cells cultured with CGRP10 $0^{-10} \mathrm{M}$ compared with that in controls (pMEK-1, 100.0 $\pm 3.7 \%$; pERK, $100.0 \pm 15.8 \%$ ) (Fig. 6).

Effects of CGRP ${ }_{8-37}$ and Rp-cAMP on ERK inhibition in Huh7 cells cultured with CGRP

To determine whether the inhibition of the CGRP receptor or CREB activation causes the reverse ERK inhibition by CGRP, Huh7 cells were precultured with $\mathrm{CGRP}_{8-37}$ or the cAMP inhibitor RpcAMP for $1 \mathrm{~h}$ and then exposed to CGRP for $24 \mathrm{~h}$. Pretreatment with CGRP $_{8-37} \quad 10^{-11}$ M (101.48 $\pm 7.14 \%)$ and $10^{-10} \mathrm{M}(101.5 \pm 7.13 \%)$ or Rp-cAMP $10^{-7} \mathrm{M}(82.4 \pm 12.4 \%)$ tended to reverse ERK inhibition $(71.4 \pm 10.22 \%)$ in cells cultured with CGRP, suggesting that CGRP inhibits the MAP pathway through cAMP-dependent activation (Fig. 7). 
A

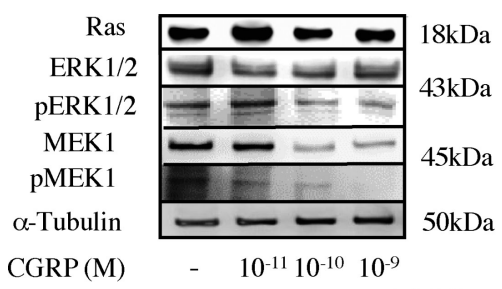

ERK
B

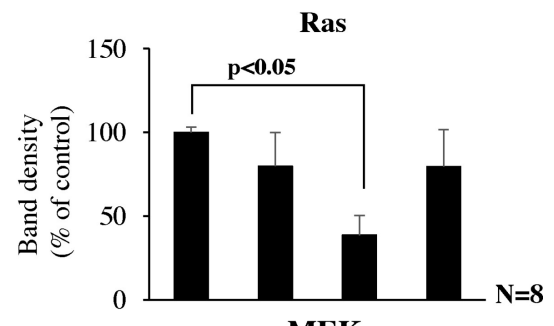

MEK
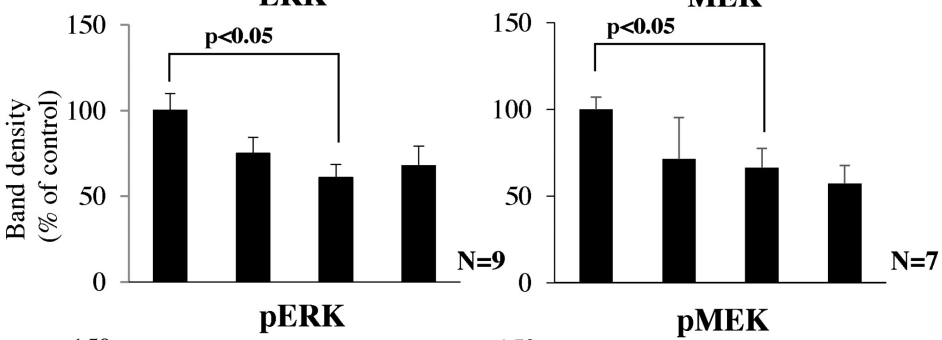

pMEK

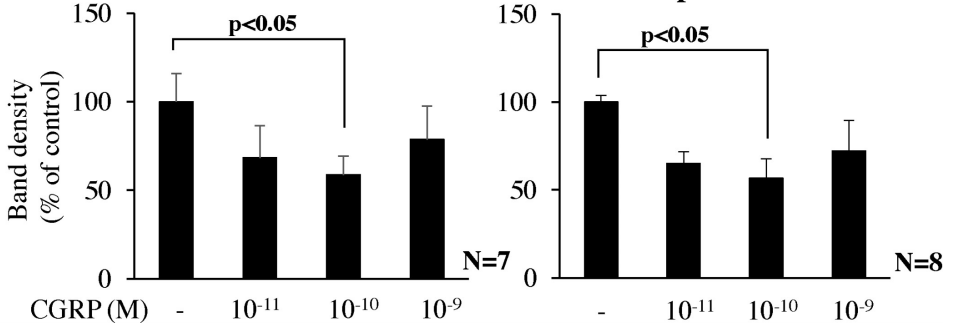

Figure 6. Total and phosphorylated protein levels of Ras, ERK, and MEK-1 in Huh7 cells cultured with CGRP. Huh7 cells were cultured with CGRP for $24 \mathrm{~h}$ and then the protein levels of Ras, MEK-1, and ERK1/2 were analyzed using Western blotting. (A) Images shown are from a representative Western blotting experiment. (B) Data are expressed as the percentage of CGRP-cultured cells to that of controls. $p<0.05$ versus controls.

\section{Discussion}

This study showed that CGRP inhibited cell proliferation through the Ras/MEK/ERK pathway in HCC cell lines. In addition, CGRP exerts its activity via the CGRP receptor and CREB activation. The rationale for this study was based on reports that the liver is densely innervated, including abundant CGRP-immunoreactive neurons of spinal afferent origin $^{7}$. CGRP and its receptor are also expressed in hepatocytes and nonparenchymal hepatic cells ${ }^{14}$. CGRP was reported to contribute to systemic vasodilatation in cirrhosis and in cholangiocyte proliferation during cholestasis ${ }^{15), 16)}$. CGRP is closely involved in the pathogenesis of liver disease. On the other hand, CGRP reduces the production of proinflammatory cytokines and prevents inflammatory liver damage ${ }^{17)}$. Therefore, CGRP mediates both pro- and anti-inflam- matory activities. Neuropeptides are known to play important roles in cancer such as tumor cell proliferation, antiapoptotic effects, and migration of tumor cells for inversion and metastasis ${ }^{18), 19}$. Although the roles of CGRP in liver disease have been investigated previously, the relationship between CGRP and HCC pathogenesis remains unknown.

We first studied the expression of CGRP and its receptor in HCC tissues with various etiological factors, i.e., HBV, HCV, and non-B, non-C infection. Nerve fibers containing CGRP are present in the perivascular nerve bundles running through the large interlobular hepatic blood vessels ${ }^{20)}$. Although prominent localization of CGRP in the tissues of normal liver and liver metastasis of colorectal cancer was not observed, CGRP immunoreactivity was high in the HCC tissues examined. CGRP immunoreactivity was seen in both tumorous and nontumorous regions and 


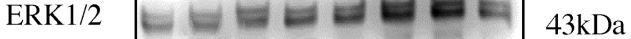
a-Tubulin 50kDa

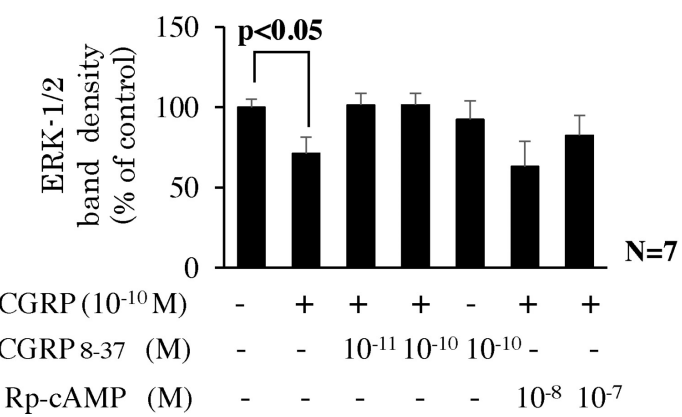

Figure 7. Effects of $\mathrm{CGRP}_{8-37}$ and the cAMP/CREB inhibitor Rp-cAMPS on protein levels of ERK in Huh7 cells cultured with CGRP. Huh7 cells were precultured with $\mathrm{CGRP}_{8-37}\left(10^{-11} \mathrm{M}\right.$ and $\left.10^{-10} \mathrm{M}\right)$ or Rp-cAMPS $\left(10^{-8} \mathrm{M}\right.$ or $\left.10^{-7} \mathrm{M}\right)$ for 1 $\mathrm{h}$, followed by $24 \mathrm{~h}$ incubation with CGRP, and then the cells were analyzed using Western blotting.

Data are expressed as mean \pm SEM and representative of 7 independent experiments. $* p<$ 0.05 versus CGRP $10^{-10}$ M-cultured cells. $p<0.05$ versus control.

was strong on the periphery of the intrahepatic blood vessels of HCC tissues. In addition, we found that CGRP was produced by HCC cells. CGRP has specific functional receptors. The mRNA expression of CLR and RAMP-1 was confirmed using RT-PCR in HCC cells and the HCC cell line in the present study. Both CLR and RAMP-1 mRNA were expressed in normal liver, the nontumorous region of HCC liver tissue, Huh7cells, and HepG2 cells, although the expression in the tumorous region of HCC tissue was relatively weak. CGRP receptor mRNA levels are not altered by physiological stimulation such as inflammation $^{21,22)}$. One reasons is considered to be the presence of necrotic tissue within the tumorous region in HCC samples. Another reason is that expressions of CGRP receptors are decreased in the presence of liver cancer. Further study is needed concerning whether the expressions of CGRP receptors decrease in hepatic carcinogenesis of animal models. CGRP increased the production of proinflammatory cytokines in murine macrophages and splenocytes ${ }^{23,24)}$. On the other hand, CGRP also inhibits nuclear factor $\kappa \mathrm{B}$ activation, thereby down-modulating the production of tumor necrosis factor- $\alpha^{25}$. Umeda et al. repor- ted the inhibition of mitogen-stimulated $\mathrm{T}$ lymphocyte proliferation by CGRP ${ }^{26}$. CGRP thus exerts both antiinflammatory and pro-inflammatory effects.

To clarify the effects of CGRP on HCC cell proliferation, Huh7 and HepG2 cells were cultured for $24 \mathrm{~h}$ with CGRP at concentrations ranging from $10^{-12}$ $\mathrm{M}$ to $10^{-8} \mathrm{M}$. Maximal inhibitory effects on cell proliferation occurred at the physiological concentration of CGRP $10^{-10} \mathrm{M}$. Bell-shaped concentration-response curves were obtained after culture with CGRP at high concentrations of $10^{-9} \mathrm{M}$ and $10^{-8} \mathrm{M}$. This may be attributable to receptor desensitization due to internalization and depletion of the second messenger. Because greater inhibition of Huh7 cells was observed compared with HepG2 cells, subsequent experiments focused on Huh7 cells.

CGRP can upregulate CREB and its phosphorylation on ser-133 in the rat brain with ischemic neurons $^{27}$. Our data showed that the protein levels of total CREB and pCREB in the nuclei of Huh7 cells cultured with $10^{-10} \mathrm{M}$ CGRP were significantly higher than those in control cells, consistent with previous reports. Activated CGRP receptors stimulate adenylyl cyclase activity and phospholipase $\mathrm{C}$, stimulatating cAMP production and the activation of protein kinase A (PKA), respectively. CRE is essential for the response of the calcitonin/CGRP gene promoter ${ }^{12,13)}$. Villa et al. reported that CGRP enhances PKA activity in human osteoblast-like cells and inhibits osteoprotegrin production through the CGRP receptor ${ }^{28)}$. To examine whether CREB activation in cells cultured with CGRP mediates the CGRP receptor, Huh7 cells were precultured with the CGRP receptor antagonist $\mathrm{CGRP}_{8-37}$, followed by culture with CGRP $10^{-10} \mathrm{M}$. CGRP ${ }_{8-37} 10^{-11}$ and $10^{-10} \mathrm{M}$ abolished the increases in CREB and pCREB protein levels in CGRP $10^{-10} \mathrm{M}$-cultured cells. These results demonstrate that CGRP stimulates CREB activation through the CGRP receptor in HCC cells. One target of cAMP/CREB associated with tumor cell proliferation is the MAPK cascade ${ }^{29}$. cAMP/CREB activation inhibited cell mitogenesis, and the phenomenon was dependent on ERK-MAPK signaling in a rat HCC model $^{30)}$. Ras/Ras families of oncogenes are transforming genes, and the Ras/Raf/MEK/ERK cascade has important roles in cell proliferation, differentiation, malignant transformation, and apoptosis ${ }^{3132}$. MAPK signaling is critical in HCC tumorigenesis ${ }^{33)}$. The anticancer drug 5-fluorouracil combined with the multikinase inhibitor sorafenib inhibits MAPK and STAT3 signaling in HCC cells ${ }^{34}$. Our data showed 
that CGRP $10^{-10} \mathrm{M}$ significantly decreased Ras protein levels. In addition, the decreases in MEK and ERK protein levels were accompanied by their reduced phosphorylation. These results suggest that CGRP exerts antitumor effects by inhibiting the MAPK cascade in HCC.

Our results also showed that culture with $\mathrm{CGRP}_{8-37} 10^{-11} \mathrm{M}$ and $10^{-10} \mathrm{M}$ or with the cAMP inhibitor Rp-cAMP10 ${ }^{-7} \mathrm{M}$ tended to reverse the ERK inhibition in cells cultured with CGRP, suggesting that CGRP inhibits the MAPK cascade through the CGRP receptor and cAMP-dependent activation.

In conclusion, our results demonstrated the inhibitory mechanisms of CGRP on tumor cell proliferation in HCC. CGRP blocks tumor cell proliferation by targeting the CREB-dependent Ras/MAPK cascade.

The decrease of adverse effects is an important problem in the multidisciplinary opinions including combination chemotherapeutic agents for HCC treatment. Because CGRP is a biological active substance in a living body, CGRP seem to have few pharmacological side effects and enables long term administration for cancer treatment. CGRP $10^{-10} \mathrm{M}$ significantly inhibited cell proliferation in HCC cell line although the action was weak. One idea for future study is the combined use of CGRP and anticancer agents.

However, it is necessary to clarify whether CGRP is effective in modulating the progression of HCC in human primary cultured cancer cells and animal models in vivo in the future. These findings may lead to promising new pharmacological strategies to inhibit tumor development and progression.

\section{References}

1) Chrousos GP, Gold PW. The concepts of stress and stress system disorders. Overview of physical and behavioral homeostasis. JAMA 1992; 267: 1244-1252.

2) Seeman TE, Singer BH, Rowe JW, Horwitz RI, McEwen BS. Price of adaptation--allostatic load and its health consequences. MacArthur studies of successful aging. Arch Intern Med 1997; 157: 2259-2268.

3) McEwen BS, Stellar E. Stress and the individual. Mechanisms leading to disease. Arch Intern Med. 1993; 153: 2093-2101.

4) Cochaud S, Chevrier L, Meunier AC, Brillet T, Chadéneau C, Muller JM. The vasoactive intestinal peptide-receptor system is involved in human glioblastoma cell migration. Neuropeptides
2010; 44: 373-383

5) Epstein RJ, Leung TW. Reversing hepatocellular carcinoma progression by using networked biological therapies. Clin Cancer Res 2007; 13: 11-17.

6) Geppetti P, Capone JG, Trevisani M, Nicoletti P, Zagli G, Tola MR. CGRP and migraine: neurogenic inflammation revisited. J Headache Pain 2005; 6: 61-70.

7) Goehler LE1, Sternini C. Calcitonin gene-related peptide innervation of the rat hepatobiliary system. Peptides 1996; 17: 209-217.

8) Reubi JC. Neuropeptide receptors in health and disease: the molecular basis for in vivo imaging. J Nucl Med 1995; 36: 1825-1835.

9) Borbath I, Leclercq IA, Abarca-Quinones J, Desaeger C, Lebrun V, Moulin P, Sempoux C, Horsmans Y. Inhibition of early preneoplastic events in the rat liver by the somatostatin analog lanreotide. Cancer Sci 2007; 98: 1831-1939.

10) Verhoef C, van Dekken H, Hofland LJ, Zondervan PE, de Wilt JH, van Marion R, de Man RA, IJzermans JN, van Eijck CH. Somatostatin receptor in human hepatocellular carcinomas: biological, patient and tumor characteristics. Dig Surg 2008; 25: 21-26.

11) Cottrell GS, Padilla B, Pikios $S$, Roosterman D, Steinhoff M, Grady EF, Bunnett NW. Post-endocytic sorting of calcitonin receptor-like receptor and receptor activity-modifying protein 1 . J Biol Chem 2007; 282: 12260-12271.

12) Burbach JP, Meijer OC. The structure of neuropeptide receptors. Eur J Pharmacol 1992; 227: 1-18.

13) Freeland K, Liu YZ, Latchman DS. Distinct signalling pathways mediate the cAMP response element (CRE)-dependent activation of the calcitonin gene-related peptide gene promoter by cAMP and nerve growth factor. Biochem $\mathrm{J}$ 2000; 345: 233-238.

14) Bracq S, Clement B, Pidoux E, Moukhtar MS, Jullienne A. CGRP is expressed in primary cultures of human hepatocytes and in normal liver. FEBS Lett 1994; 351: 63-66.

15) Møller S, Bendtsen F, Schifter S, Henriksen JH. Relation of calcitonin gene-related peptide to systemic vasodilatation and central hypovolaemia in cirrhosis. Scand J Gastroenterol 1996; 31: 928-933.

16) Glaser SS, Ueno Y, DeMorrow S, Chiasson VL, Katki KA, Venter J, Francis HL, Dickerson IM, 
DiPette DJ, Supowit SC, Alpini GD. Knockout of alpha-calcitonin gene-related peptide reduces cholangiocyte proliferation in bile duct ligated mice. Lab Invest 2007; 87: 914-926.

17) Kroeger I, Erhardt A, Abt D, Fischer M, Biburger M, Rau T, Neuhuber WL, Tiegs G, The neuropeptide calcitonin gene-related peptide (CGRP) prevents inflammatory liver injury in mice. J Hepatol 2009; 51: 342-353.

18) $\mathrm{Xu} \mathrm{XT}, \mathrm{Xu} \mathrm{B}$, Song QB, Zeng H. The role of neural-related factors in the metastasis of the gastrointestinal cancer. J Cancer Res Ther 2013; 9: S123-S128.

19) Muñoz M, Coveñas R. Involvement of substance $\mathrm{P}$ and the NK-1 receptor in human pathology. Amino Acids 2014; 46: 1727-1750.

20) Ashraf S, Crowe R, Loizidou MC, Turmaine M, Taylor I, Burnstock G. The absence of autonomic perivascular nerves in human colorectal liver metastases. Br J Cancer 1996; 73: 349359.

21) Clifton MS, Hoy JJ, Chang J, Idumalla PS, Fakhruddin H, Grady EF, Dada S, Corvera CU, Bhargava A. Role of calcitonin receptor-like receptor in colonic motility and inflammation. Am J Physiol Gastrointest Liver Physiol 2007; 293: G36-G44.

22) Shi X, Wang L, Clark JD, Kingery WS. Keratinocytes express cytokines and nerve growth factor in response to neuropeptide activation of the ERK1/2 and JNK MAPK transcription pathways. Regul Pept 2013; 186: 92-103.

23) Tang Y, Feng Y, Wang X. Calcitonin gene-related peptide potentiates LPS-induced IL-6 release from mouse peritoneal macrophages. J Neuroimmunol 1998; 84: 207-212.

24) Ahmed AA, Mutt V, Nordlind K. Modulating effects of sensory and autonomic neuropeptides on murine splenocyte proliferation and cytokine secretion induced by Leishmania major. Immunopharmacol Immunotoxicol 1999; 21: 507526.

25) Millet I, Phillips RJ, Sherwin RS, Ghosh S, Voll R, Flavell RA, Vignery A, Rincón M. Inhibition of NF-kappaB activity and enhancement of apoptosis by the neuropeptide calcitonin gene- related peptide. J Biol Chem 2000; 275: 15114 15121.

26) Umeda $Y$, Takamiya M, Yoshizaki H, Arisawa M. Inhibition of mitogen-stimulated T lymphocyte proliferation by calcitonin gene-related peptide. Biochem Biophys Res Commun 1988; 154: 227-235.

27) Zhang ZH, Fang XB, Xi GM, Li WC, Ling HY, $\mathrm{Qu}$ P. Calcitonin gene-related peptide enhances CREB phosphorylation and attenuates tau protein phosphorylation in rat brain during focal cerebral ischemia/reperfusion. Biomed Pharmacother 2010; 64: 430-436.

28) Villa I, Mrak E, Rubinacci A, Ravasi F, Guidobono F. CGRP inhibits osteoprotegerin production in human osteoblast-like cells via cAMP/ PKA-dependent pathway. Am J Physiol Cell Physiol 2006; 291: C529-C537.

29) Stork PJ, Schmitt JM. Crosstalk between cAMP and MAP kinase signaling in the regulation of cell proliferation. Trends Cell Biol 2002; 12: 258-266.

30) Kovach SJ, Price JA, Shaw CM, Theodorakis NG, McKillop IH. Role of cyclic-AMP responsive element binding (CREB) proteins in cell proliferation in a rat model of hepatocellular carcinoma. J Cell Physiol 2006; 206: 411-419.

31) McCubrey JA, Steelman LS, Franklin RA, Abrams SL, Chappell WH, Wong EW, Lehmann BD, Terrian DM, Basecke J, Stivala F, Libra M, Evangelisti C, Martelli AM. Targeting the RAF/MEK/ERK, PI3K/AKT and p53 pathways in hematopoietic drug resistance. Adv Enzyme Regul 2007; 47: 64-103.

32) Cagnol S, Chambard JC. ERK and cell death: mechanisms of ERK-induced cell death--apoptosis, autophagy and senescence. FEBS J 2010; 277: 2-21.

33) Wiesenauer CA, Yip-Schneiderca MT, Wang Y, Schmidt CM. J Am Coll Surg 2004; 198: 410421.

34) Deng L, Ren Z, Jia Q, Wu W, Shen H, Wang Y. Schedule-dependent antitumor effects of 5-fluorouracil combined with sorafenib in hepatocellular carcinoma. BMC Cancer 2013; 13: 363. 